\title{
A RECEPÇÃO DE FOUCAULT NO DIAGNÓSTICO DO NEOLIBERALISMO DE WENDY BROWN
}

Heitor Moreira Lurine Guimarães ${ }^{I}$

Resumo: O artigo tem como objetivo analisar as interpretações feitas da obra de Michel Foucault por Wendy Brown na formulação de seu diagnóstico a respeito do neoliberalismo enquanto forma de racionalidade política. Em suas publicações ao longo das últimas duas décadas, Brown dedicou-se a estudar o fenômeno do neoliberalismo, com ênfase em suas implicações para as instituições e valores democráticos. Embora, em todos esses escritos, o pensamento de Foucault figure explicitamente como referencial teórico central, é possível perceber nuances na forma como a autora se apropria de suas ideias e as utiliza como premissas de análise da conjuntura política presente. Nesse sentido, por meio de um exame de alguns dos textos mais relevantes da autora a esse respeito, o artigo busca captar essas variações na sua leitura de Foucault para fins de elaboração de suas teses. Mais especificamente, os textos analisados consistem em dois artigos publicados por Brown sobre o neoliberalismo nos anos 2000 , e uma monografia posterior.

Palavras-chave: Wendy Brown. Foucault. Neoliberalismo

\section{THE RECEPTION OF FOUCAULT IN WENDY BROWN'S DIAGNOSIS OF NEOLIBERALISM}

Abstract: The article aims to analyze the interpretations of Michel Foucault made by Wendy Brown in the formulation of her diagnosis regarding neoliberalism as a kind of political rationality. In her publications throughout the last two decades, Brown has dedicated herself to study the phenomenon of neoliberalism, mainly its implications to democratic institutions and values. Although, in most of her writings, Foucault's thought figures explicitly as main theoretical reference, it is possible to notice nuances in the way how Brown receives his ideas and uses them as analytical premises to the current political conjuncture. Thus, by means of examination of some of her main writings related to this theme, the article seeks to capture these variations in her reading of Foucault to elaborate her theses. More specifically, the texts analyzed consist of two articles on neoliberalism published by Brown in the 2000s and a later monography.

Keywords: Wendy Brown. Foucault. Neoliberalism.

1 Graduando do curso de Bacharelado em Direito pela Universidade Federal do Pará. Email: hguimaraes631@gmail.com. Currículo Lattes: http://lattes.cnpq.br/2747211640060233. 


\section{Introdução}

A expressão neoliberalismo, nas últimas décadas, tornou-se um vocábulo frequente nas discussões e debates em teoria social, ciência política e filosofia de matriz crítica. Enquanto acontecimento político próprio da segunda metade do século XX, o neoliberalismo é comumente associado a políticas de privatização do patrimônio público, de minimização do papel do Estado, de ojeriza a todo tipo de assistencialismo governamental, dentre outras diretrizes. Em termos de figuras importantes para sua implementação, os nomes que imediatamente vêm à mente são os de Margaret Thatcher e de Ronald Reagan. No plano das ideias e das teorias econômicas, são centrais os nomes de Friedrich Hayek, Ludwig von Mises, Milton Friedman, dentre outros.

Apesar disso, a própria definição sobre o que significa o conceito de neoliberalismo é objeto de controvérsia. Dentre as várias abordagens que pretendem dar uma resposta a essa questão, destaca-se a de Wendy Brown. Professora de Ciência Política na Universidade da Califórnia, Brown se tornou famosa pela elaboração de estudos rigorosos sobre como o neoliberalismo promove uma desconstrução da democracia enquanto regime político, fenômeno por ela denominado de desdemocratização ${ }^{2}$, que consiste na maneira como os valores orientadores da práxis democrática são substituídos um a um por valores meramente econômicos.

Ao longo do percurso de desenvolvimento de seu pensamento, a figura de Michel Foucault sempre se mostrou como um referencial relevante. Mais especificamente, os estudos de Brown a respeito do capitalismo neoliberal tomam como ponto de partida as premissas estabelecidas por Foucault sobre o neoliberalismo. Esse autor, recusando-se a se conformar com uma visão marxista a respeito do tema, inaugura uma nova abordagem à luz da qual o neoliberalismo é compreendido como uma nova forma de controle das condutas dos indivíduos, de produção da verdade e, acima de tudo, de produção de subjetividade.

Embora Brown afirme que a perspectiva oferecida por Foucault é fecunda e especialmente elucidativa para se elaborar uma explicação a respeito do momento presente, a leitura e o uso que a autora faz de seus conceitos para a produção de um diagnóstico sobre a atualidade aparenta ter passado por modificações substanciais entre seus primeiros escritos e seu trabalho posterior, mais consolidado. O que este artigo pretende é, desse modo, analisar como Wendy Brown recepcionou o trabalho de Foucault sobre o neoliberalismo nas várias versões em que seu diagnóstico foi formulado.

\footnotetext{
${ }^{2}$ Expressão aqui empregada como tradução livre para o termo dedemocratization
} 
Para tanto, começa-se com um exame das primeiras publicações de Brown pertinentes a essa temática, nas quais uma tentativa de se apropriar da visão de Foucault é esboçada. Trata-se de dois artigos, um de 2003, o outro de 2006, em que Wendy Brown pelas primeiras vezes estabelece a conexão entre o neoliberalismo, suas repercussões políticas e as ameaças colocadas à democracia liberal. Como ficará explícito, tais artigos são marcados pelo tipo de política interna e externa adotada durante o período de G.W. Bush à frente do governo estadunidense. E, dado que esse contexto histórico participa da compreensão dos argumentos nos textos, eles serão tratados, para fins de periodização e organização temporal, neste artigo, sob a categoria de "escritos da era Bush".

$\mathrm{Na}$ sequência, o presente trabalho se ocupa de discutir alguns dos resultados da pesquisa conduzida por Wendy Brown que culminaram na publicação da importante obra "Undoing the Demos", em que a noção de desdemocratização é aperfeiçoada e trabalhada em detalhes em relação ao contexto dos Estados Unidos. Busca-se evidenciar de que maneira essa produção posterior de Brown é bem mais crítica e problematizadora em relação à leitura foucaultiana do neoliberalismo, ao mesmo tempo em que é capaz de refinar alguns dos apontamentos de Foucault e transformá-los em chave de compreensão de uma série de fenômenos políticos atuais.

\section{Escritos da era Bush}

Segundo o percurso há pouco definido, os primeiros dois textos de que iremos nos ocupar consistem em dois artigos publicados por Wendy Brown em periódicos estadunidenses, na primeira metade da década passada. $\mathrm{O}$ primeiro deles tem como título "Neoliberalism And The End of Liberal Democracy", publicado inicialmente na revista Theory and Event em 2003. Posteriormente foi republicado na coletânea "Edgework: critical essays on knowledge and politics", em 2005, e é esta versão que será usada como referência aqui. O segundo, chamado "American Nightmare: Neoliberalism, Neoconservatism And DeDemocratization”, encontra-se publicado pela revista Political Theory, desde 2006.

Ambos os textos contêm formulações iniciais dos argumentos mais importantes que viriam a emergir na obra madura da autora, e já esboçam a preocupação que anima todas as obras a serem tratadas neste trabalho: o efeito de desmantelamento do neoliberalismo sobre a democracia em suas formas liberais contemporâneas. Também, como anunciado na introdução, os artigos são aqui classificados como pertencentes à "Era Bush" em função de que todos dois têm como horizonte histórico exatamente o tipo de autoritarismo que se 
relevou nos Estados Unidos no período imediatamente posterior ao episódio do World Trade Center.

\section{Uma nova racionalidade}

No primeiro texto, Brown tem como primeiro objetivo construir uma caracterização do neoliberalismo que fuja às descrições mais superficiais a respeito desse fenômeno político, a saber, aquelas que o compreendem como um conjunto específico de doutrinas econômicas simpáticas à iniciativa privada, que consideram como perniciosa e alienante toda forma de assistencialismo governamental e que promovem o alinhamento da política estatal interna com instituições financeiras internacionais como Banco Mundial e FMI.

Obviamente que não se trata de diminuir a relevância de cada uma dessas características e de como elas contribuem para o aprofundamento das desigualdades sociais. Em um outro influente estudo sobre o tema, David Harvey (2014) propõe que o neoliberalismo teria sido um projeto de renovação do capitalismo para contornar crises ocorridas da década de 1960 em diante, e que sistematicamente beneficiou as elites econômicas internacionais. O que Wendy Brown (2005) propõe, em vez disso, é que a essa interpretação escapa justamente o elemento distinto que justifica o prefixo "neo" na nomenclatura neoliberalismo. Como consequência, tende a reduzi-lo a uma manifestação revigorada do liberalismo clássico, um velho personagem da histórica do pensamento econômico ocidental, que teria, então, sido convenientemente readaptado para se coadunar com as condições da nova ordem mundial e cumprir seu tradicional papel de justificador do status quo.

A tarefa que Brown chama para si, nesse sentido, é a de demonstrar como cada um desses traços está situado no interior de um projeto de dominação cuja essência pode ser definida na forma do estabelecimento de uma nova racionalidade política. Ou seja, mostrar como aquilo que chamamos de neoliberalismo inaugura não apenas novas configurações das relações de trabalho e produção, mas, antes de tudo, um novo paradigma normativo a partir do qual se define a distinção entre o racional e o irracional, entre o normal e o patológico, entre o legítimo e o ilegítimo, entre o verdadeiro e o falso. E é exatamente nesse ponto que Foucault entra em cena. Assim, para que se possa proceder à análise dos argumentos de Brown, é preciso antes fazer algumas considerações sobre as análises do autor a esse respeito.

O tema do neoliberalismo surge na obra de Foucault como um desdobramento do seu trabalho a respeito do biopoder. No capítulo final do primeiro volume de História da Sexualidade, de 1976, Foucault famosamente afirmou que a passagem para a modernidade 
trouxe consigo uma nova forma de poder que não se deixa explicar de modo algum pelo viés da repressão ou da coerção. Ao contrário do poder soberano, existente desde a idade clássica, e que tem como maior manifestação o poder de provocar a morte, essa nova modalidade de poder se caracteriza por promover e organizar a vida. Não se tratava mais de suprimir ou de aniquilar a vida, mas de tomar os processos vitais como objeto de regulação a serem mensurados, geridos e administrados. Foucault sintetiza essa mudança histórica dizendo que o poder soberano tinha sua essência definida pela máxima "fazer morrer e deixar viver", ao posso que o advento do biopoder caracteriza-se por ser "um poder exatamente inverso: poder de 'fazer' viver e de 'deixar' morrer” (FOUCAULT, 2010, p. 202).

Esse novo poder sobre a vida, para Foucault, manifesta-se fundamentalmente de duas maneiras. A primeira delas, já analisada detalhadamente sobretudo em Vigiar e Punir e nos cursos da primeira metade da década de 1970, consiste em uma certa técnica de dispor os indivíduos no espaço, submetê-los a determinadas tarefas e atividades repetitivas e administrar o uso do tempo. Seu propósito último é o de promover um treinamento e um adestramento do corpo, de modo a ajustá-lo a um certo padrão de normalidade, uniformizando os comportamentos dos indivíduos e tornando-os obedientes. Dado que este poder se exerce muito mais pela construção de hábitos e correção de condutas do que propriamente pelo castigo, Foucault o denomina de poder disciplinar, ou simplesmente de disciplinas. Encontrase na base de uma diversidade de instituições, como o hospital, a escola, o quartel, a fábrica e a prisão (FOUCAULT, 2018).

A segunda manifestação do biopoder, que interessa mais para os propósitos deste artigo, é o que ficou conhecido com o nome de biopolítica ${ }^{3}$. Conforme o nome sugere, trata-se aqui de uma política sobre a vida, ou seja, uma política para a qual a vida é o objeto central de administração. Se o poder disciplinar se exerce primordialmente sobre o corpo individualizado, a biopolítica atua não sobre cada indivíduo singularmente, mas sobre populações inteiras, e sobre os fenômenos que lhe são próprios, como natalidade, mortalidade, propagação de doenças, dentre outros. Por meio do controle estatístico, a biopolítica se constitui como uma tecnologia de poder macroscópica que se ocupa de modular cada um desses processos, ordenando-os de acordo com parâmetros reputados como aceitáveis (FOUCAULT, 2018).

\footnotetext{
${ }^{3}$ A esse respeito, é necessário destacar que o próprio Foucault não é completamente uniforme no que se refere ao uso dos termos "biopoder" e "biopolítica". No primeiro volume da História da Sexualidade, biopoder parece figurar como o conceito que designa o gênero do qual o poder disciplinar e a biopolítica são espécies. Em outras obras, as expressões biopoder e biopolítica são usadas de forma aparentemente equivalente.
} 
Ao investigar a natureza desse fenômeno moderno do poder, Foucault chega à conclusão de que todo biopoder se manifesta como uma arte de governar, ou, para usar sua famosa expressão, como uma governamentalidade. O desenvolvimento desse conceito em Foucault é denso o bastante para um trabalho completo, de modo que, para os propósitos deste trabalho, devemos nos ater a apenas alguns aspectos fundamentais. Em primeiro lugar, governamentalidade designa não simplesmente o conjunto das instituições políticas existentes, mas antes o conjunto das práticas e estratégias pelas quais, em um certo contexto, a conduta dos indivíduos é conduzida em um certo sentido em vez de outro. Mais concretamente, deve-se entender aqui por "governo" todas as técnicas pelas quais os indivíduos são dirigidos quanto à sua maneira de viver, de se relacionarem com seus próprios corpos, de experimentarem o prazer, de se reproduzirem, de se relacionarem com os outros e, no limite, de conduzirem a si mesmos. Nessa linha de raciocínio, pode-se falar em uma arte de governar as crianças (pedagogia), os doentes (medicina), os loucos (psiquiatria), e assim por diante (FOUCAULT, 2008a).

É nesse diapasão que o neoliberalismo, segundo Foucault, deve ser compreendido. Como uma nova arte de governar os indivíduos, vigente na contemporaneidade e singular em relação a todas as outras anteriores. Produtora não só de mercadorias, mas principalmente de subjetividades. O propósito de sua investigação é, então, o de determinar que tipo de sujeito é produzido pela arte neoliberal de governar. Foucault aponta que há ao menos dois grandes grupos de neoliberais. Há o ordoliberalismo, vertente surgida na Alemanha na primeira metade do século XX, representado por pensadores como Eucken, Lippman, Rüstow e Röpke. E a vertente austro-americana representada por autores como Mises e Hayek, conhecidos por sua veemente rejeição a qualquer forma de socialismo e pela influência que tiveram sobre as agendas políticas neoliberais nos governos Thatcher e Reagan. Ao contrário do liberalismo clássico, o neoliberalismo, sobretudo tal como se encontra formulado em Mises, Hayek, Friedman e outros, ancora-se em um paradigma antropológico que concebe o ser humano como entidade essencialmente calculadora, que racionalmente prevê os resultados de suas ações e as planeja segundo aquilo que proporciona maior eficiência e otimização dos recursos disponíveis.

Traçar a genealogia dessa arte de governar neoliberal, que não se deixa explicar apenas como uma ideologia ou agenda econômica, é, em última instância, o objetivo do curso de 1979 "O Nascimento da Biopolítica”, principal referência do autor sobre essa temática. Mais especificamente, o que é peculiar ao projeto neoliberal, nessa linha de raciocínio, é que 
ele se ocupa de construir e naturalizar aquilo que defende já ser real. Isto é, através de sucessivas reformas dos diversos setores da sociedade, da formação educacional às políticas públicas urbanas, a arte de governar neoliberal ensina cada indivíduo a enxergar a si mesmo como um capital que precisa aumentar sua competitividade em comparação com os outros, a adotar a concorrência como o princípio norteador de todas as suas atividades e relações (profissionais ou não), em suma, a agir, conforme a célebre expressão de Foucault, como "um empresário de si mesmo" (FOUCAULT, 2008b, p. 311).

À luz dessas ideias, Wendy Brown atribui a si mesma a tarefa de explicitar quais as consequências institucionais do estabelecimento dessa nova forma de racionalidade. Em verdade, dada a fortuna editorial das aulas de Foucault no Collège de France após sua morte, essa primeira tentativa de Brown de traçar uma leitura do presente é feita através de um contato com Foucault via o trabalho de Thomas Lemke (2001), haja vista que as palestras só vieram a público na França em 2004. O texto de Lemke a esse respeito pode ser considerado como uma exposição bastante fiel e condizente com o conteúdo das apresentações de Foucault. E um dos elementos enfatizados pelo alemão em seu estudo é justamente como o neoliberalismo consiste em um novo paradigma epistemológico a partir do qual a realidade é vislumbrada.

A exposição feita por Lemke é adotada, então, por Wendy Brown, como referência a respeito das teses de Foucault. Há dois pontos especialmente significativos explanados por Lemke a respeito da obra foucaultiana dos quais Brown deseja extrair consequências nesse texto de 2005. O primeiro deles trata-se de uma novidade, demonstrada por Foucault, do neoliberalismo em relação ao liberalismo clássico: o deslocamento da troca para a concorrência como motivo central da relevância atribuída do mercado. Em autores como Smith e Ricardo, o mercado é instituição preciosa porque permite que cada um realize suas preferências por meio de trocas com outros indivíduos em condições de liberdade e igualdade. No âmbito do mercado, para esses autores clássicos, os indivíduos poderiam oferecer os produtos de seu trabalho em troca de outra mercadoria ou de uma quantia correspondente ao seu valor, de sorte que todos teriam como satisfazer suas necessidades. A intervenção estatal, por outro lado, é condenada como maléfica, na medida em que é vista como elemento que milita contra essa alocação ideal de recursos que apenas um mercado desinibido é capaz de proporcionar.

A seu turno, o neoliberalismo em geral se caracteriza por valorizar o mercado não pela possibilidade da troca, mas pelas relações de concorrência que ele produz. Isto é, pelo fato de 
engajar cada indivíduo em um esforço constante de superação dos demais na busca de seus interesses privados. Tanto para ordoliberais quando para os austro-americanos, a ausência de uma lógica de concorrência universal é o rumo mais perigoso que uma sociedade pode tomar. Isso porque, por um lado, a falta de concorrência cria uma condição viciosa, em que os indivíduos se tornam dependentes do Estado e incapazes de governas suas próprias vidas de maneira independente. Por outro, porque as pessoas se tornam suscetíveis de serem seduzidas por toda sorte de projeto autoritário baseado na supressão da liberdade em nome da nação ou do bem do povo, tal como aconteceu no caso do nazifascismo. Em outras palavras, na visão neoliberal, uma política econômica assistencialista é sempre uma antessala do totalitarismo. Contra esse mal, o melhor remédio consiste em formatar a subjetividade dos indivíduos para enxergarem a sua relação de si para com os outros sempre como uma relação de concorrência, de modo a jamais consentirem com a supressão de suas liberdades em nome de algo que não os seus propósitos individuais (FOUCAULT, 2008b; LEMKE, 2001).

O segundo ponto explicado por Foucault e acolhido por Brown representa ruptura ainda mais explícita para com os liberais clássicos. É uma tese que se encontra em importantes teóricos neoliberais, notadamente os da tradição ordoliberal alemã como Eucken e Röpke. A saber, a tese de que a concorrência e o próprio mercado não são dados naturais da realidade, e, sim, o resultado socialmente construído de uma certa forma de gestão da sociedade. Em outras palavras, o mercado e a concorrência não são vistos como desdobramento de inclinações humanas que existem por natureza. Em vez disso, são gerados de modo artificial, por meio de intervenções que devem ser muito bem orquestradas a fim de provocar a concorrência, gerir o seu crescimento, suscitá-la onde ainda não existe e impedir o seu declínio onde já está estabelecida.

Consequentemente, nessa perspectiva, o Estado tem um papel ativo fundamental a desempenhar, afirmação esta que parece antiliberal, em primeira análise. Ao Estado cabe realizar intervenções qualitativamente muito específicas. Longe do tipo de intervenção sobre a demanda ou sobre os preços prevista pela teoria keynesiana, o Estado tem a função de agir como organizador e guardião das condições de possibilidade do mercado e da concorrência. Isto é, deve agir como a entidade que produz e mantém o estado de coisas propício para o florescimento e continuidade da concorrência mercadológica. Nas palavras de Foucault ao tratar desse ponto, a concorrência, “como lógica econômica essencial só aparecerá e só produzirá seus efeitos sob certo número de condições cuidadosamente e artificialmente preparadas" (FOUCALT, 2008b, p. 164). 
Assim, no artigo de 2005, Wendy Brown abraça esses traços fundamentais do neoliberalismo e sustenta teses sobre suas consequências. Em primeiro lugar, afirma, essa nova figura do homo oeconomicus, do ser humano construído como um pequeno empreendedor de si, expande o tipo de racionalidade tipicamente mercadológica para todas as dimensões da vida humana. Essa proposição, segundo Brown (2005), não deve ser entendida no sentido simplista de uma monetização da vida humana, ou seja, a mera expansão da presença da moeda para contextos que não o do mercado. Muito mais grave do que isso, devese entendê-la no sentido de que o sujeito se torna incapaz de experimentar qualquer aspecto da sua existência que não seja pela maneira como um empreendedor lida com seus negócios. Cada escolha, cada decisão, só adquire significado na medida em que é interpretada como um investimento (que, a depender da situação, pode ser de dinheiro, de energia, de afetividade, de tempo, tudo sendo compreendido como recursos aplicáveis) cujo valor se mede segundo o retorno por ele proporcionado.

Em segundo lugar vem um ponto que Brown considera não ter sido o alvo de Foucault, e que consiste, provavelmente, na originalidade da sua apropriação da obra do filósofo. Da mesma forma como ocorre ao nível da pessoa, essa reorganização das relações e das práticas sociais segundo a forma da empresa vale também para o Estado, ou, mais especificamente, para os parâmetros normativos que guiam a atividade estatal. Se, na esfera pessoal, a vida boa é reelaborada como a maximização do valor competitivo de si mesmo, na esfera política, a boa administração é redefinida como aquela que cria o estado de coisas mais fecundo para que o mercado possa prosperar, o que passa a ser uma prioridade. Isso implica uma substituição dos valores da igualdade e da justiça social pela eficiência e pela concorrência.

Isso desincumbe o Estado de qualquer tipo de obrigação ou prestação direta aos indivíduos, que são reputados como os soberanos de suas vidas e responsáveis por sua própria prosperidade. Assim, nenhum estado de coisas quanto à distribuição de recursos, serviços ou oportunidades é considerado como ilegítimo, mas sim como resultante de decisões livres e espontâneas. Nas palavras da autora, "a saúde e o crescimento da economia são a base da legitimidade estatal” (BROWN, 2005, p. 42, tradução livre, grifos da autora).

\section{Neoliberalismo e neoconservadorismo}

Esse tema do desfazimento silente dos valores democráticos em prol de valores econômicos, cuja elaboração preliminar acabamos de expor, é transportado para o artigo de 
Brown de 2006, que começa a explorar também uma chave de compreensão para a complexa imbricação entre a razão neoliberal e as novas ondas de pensamento conservador.

Deve-se observar, desde já, que Brown não fornece uma definição exata sobre o que se deve entender por neoconservadorismo. Mas os apontamentos feitos no texto mostram que a expressão é usada para designar um fenômeno político e intelectual contemporâneo que se caracteriza pela defesa de uma agenda política tipicamente de direita nacionalista, associada a reivindicações de inspiração religiosa. Algumas de suas variadas pautas são o fechamento de fronteiras a imigrantes, a imposição da moralidade cristã quanto ao casamento e à família, defesa do ensino religioso confessional e a oposição veemente a políticas de ações afirmativas, movimentos identitários, bem como qualquer forma de socialismo. No plano das ideias, destaca-se o nome de Irving Kristol como defensor declarado do neoconservadorismo. Nesse texto em particular, o alvo da argumentação de Brown é o projeto neoconservador tal como ele se apresenta nos Estados Unidos.

Assim, no segundo artigo mencionado, Brown se apoia nos apontamentos feitos naquele anterior para tentar explicar como é possível que convivam, dentro de uma mesma conjuntura, o neoliberalismo e o neoconservadorismo, já que se trata de dois projetos em vários pontos incompatíveis. Isso porque um propõe uma racionalidade abstrata e formal, e o outro propõe uma agenda de valores substantivos moralizantes; um está disposto a qualquer mudança necessária em nome da eficiência, e outro repele toda mudança que se desfaça da tradição; um defende a liberdade do mercado de crescer em todos os sentidos que forem possíveis, e outro acredita que há certos bens que não podem ter seu valor apreciado apenas em termos de lucratividade (BROWN, 2006).

Ocorre, porém, que os dois aspectos não apenas coexistem como também se reforçam mutuamente. A agenda política de G.W. Bush era, ao mesmo tempo, neoliberal (no que se refere ao fornecimento de crédito, intervenção do Estado na economia e benefícios sociais) e neoconservadora (no que se refere às relações internacionais, política migratória e tratamento a grupos minoritários).

A resposta dada por Wendy Brown (2006) para essa problemática de como os dois aspectos podem existir lado a lado depende crucialmente de que se compreenda o neoliberalismo como um tipo específico de racionalidade, o que novamente nos remete à perspectiva oferecida por Foucault. Nesse sentido, Brown afirma que a realização do projeto neoliberal, embora a princípio não tivesse essa pretensão, gera o efeito colateral de criar a abertura de que as ideologias neoconservadoras precisam para terem condições de reivindicar 
um espaço nas instituições e tentar forçá-las a se conformarem com a sua tábua de valores tradicionais.

Isso ocorre exatamente porque, quando o Estado é transformado pelo neoliberalismo em um simples aparato burocrático de fomento à concorrência e ao mercado, ele também acaba sendo despojado de compromissos ético ou morais substantivos com dignidade humana e igualdade material. O único compromisso ético do neoliberalismo é com a ideia de que as condições de vida de cada pessoa são reflexo de seu mérito em ser gestora de sua própria existência, de modo que todo tipo de assistencialismo é moralmente condenável. Em outras palavras, ao ser convertido em um veículo de produção da eficiência, o Estado tem o espírito da democracia liberal paulatinamente expulso de si, resultando em um esvaziamento dos valores que orientam as instituições. Essa fragilização produz a possibilidade de que qualquer outro grupo capaz de alcançar uma posição hegemônica converta as instituições em mero instrumento de realização de seus projetos (BROWN, 2006).

A esse respeito, o argumento de Brown mostra-se fortemente pertinente. Afinal, seria somente através de um processo de esvaziamento silencioso como esse que o termo "democracia" poderia se tornar tão maleável e distorcido a ponto de que a ocupação do Iraque pelo governo Bush pudesse ser apresentada publicamente como uma medida em defesa da "democracia" nos territórios ocupados. Esse talvez seja um dos melhores exemplos de como a desdemocratização pode funcionar como instrumento de legitimação da violência. É dessa maneira, também, que os efeitos catastróficos de políticas de alteridade fiscal em relação à população pobre e periférica podem ser progressivamente naturalizados. O mesmo ocorre quanto à perseguição explícita em relação a imigrantes, minorias raciais e étnicas de forma completamente declarada tal como se observa nos Estados Unidos, na Ucrânia e na Hungria atualmente.

Devemos observar, então, que essa chave de compreensão do casamento entre neoliberalismo e neoconservadorismo só é possível na medida em que, a partir de Foucault, o neoliberalismo seja interpretado como um fenômeno que produz, dentre outras coisas, um novo domínio de formações discursivas. Nessa toada, a tese levantada pela autora nesse ponto de sua obra avança de uma leitura de Foucault para a formulação de uma perspectiva própria. Isso porque ela dá um passo além do filósofo francês e enxerga no neoliberalismo concreto não apenas um projeto em curso, como também aberturas residuais que funcionam como oportunidades para a ação de forças igualmente letais para a democracia, mas que não faziam parte do escopo inicial do neoliberalismo (BROWN, 2006). 
Ou seja, trata-se, nesse ponto, de como a construção de um novo conjunto de categorias (como eficiência, concorrência e capital humano) que, quando tornadas os parâmetros de organização das instituições políticas, apagam todos os valores democráticos substantivos. Isso porque uma visão de mundo neoliberal favorece a tecnocracia sobre a representatividade popular; a concorrência sobre a equidade; o mercado desinibido sobre as assimetrias da vida privada. $\mathrm{O}$ neoconservadorismo se apoia no alijamento de todos esses aspectos basilares da própria ideia de regime democrático para trazer ao âmbito político cada uma de suas agendas, que, de outra maneira, pareceriam translucidamente antidemocráticas e indefensáveis. Nesse sentido, esse potencial erosivo da razão neoliberal, que também é impotente para barrar a intromissão de outras racionalidades paralelas, é a maneira peculiar como Wendy Brown desdobra o tema foucaultiano da imbricação entre saber e poder.

\section{Diagnóstico posterior e críticas a Foucault}

Pelas considerações feitas até aqui, já foi possível constatar que a recepção de Foucault nas primeiras tentativas de Wendy Brown de tomá-lo como referência para tratar do neoliberalismo contemporâneo foi bastante positiva. Quer dizer, a autora não apenas considerou que a genealogia foucaultiana fosse um arcabouço teórico interessante para captar o ineditismo da arte de governar neoliberal como também extraiu consequências importantes que não estavam abarcadas pelas palestras de Foucault.

Contudo, como ela própria viria a reconhecer, foi só mais tardiamente que suas críticas à abordagem de Foucault começaram a despontar. Em sua obra mais madura, "Undoing The Demos: Neoliberalism's Stealth Revolution”, de 2015, observa-se uma Wendy Brown para quem os méritos das palestras de 1979 no Collège de France possuem limites sérios e que precisam ser enfrentados para a formulação de um diagnóstico verdadeiramente adequado de como o neoliberalismo funciona contemporaneamente. Também não se pode deixar de mencionar que entre os dois períodos do trabalho de Brown houve a crise de 2008, ponto de inflexão fundamental da história do neoliberalismo, e cujos desdobramentos escapam ao escopo da abordagem foucaultiana original. A começar, por exemplo, pela imposição mais rígida de regimes de austeridade fiscal desde então.

Além disso, as mudanças feitas por Brown têm a ver com o fato de que apenas nessa oportunidade o texto apresentado por Foucault em seu curso já estava disponível publicamente, o que obviamente permitiu um contato mais direito com suas ideias e com os eventuais pontos fracos delas. É preciso manter em mente, como já dito, que as primeiras tentativas de Brown de teorizar a partir de Foucault dependeram de comentadores e autores 
intermediários, dada a fortuna editorial dos escritos foucaultianos. Dessa maneira, certamente houve limitações que apenas o contato direto com os textos originais trouxe à tona. Um aspecto relevante nesse sentido é que Brown, nos artigos abordados, opta por não incluir em sua argumentação as diferenciações que Foucault (2008b) fizera entre os ordoliberais e os neoliberais austro-americanos, em que pese essas distinções tenham sido explicitadas também por Lemke (2001).

Por outro lado, mesmo em alguns pontos em que Wendy Brown acredita que Foucault tenha razão, ela considera que existem aspectos de seus apontamentos que só poderiam ser formulados com precisão a partir do amadurecimento do neoliberalismo, o que Foucault, por ter falecido ainda na década de 1980, não teve possibilidade de conhecer. Desse modo, nessa nova obra, Brown dá continuidade aos seus trabalhos anteriores enriquecendo-os com essas considerações críticas.

\section{A política convertida em economia}

Interessante é o fato de que Brown (2015) inicie sua argumentação por meio de uma analogia com a filosofia política platônica. É amplamente conhecido que, em "A República", Platão estabelece que a estrutura da cidade justa é aquela que reproduz, na escala macroscópica da política, a mesma tripartição existente na alma humana. Tendo em mente esse paradigma, a teórica propõe que o fenômeno da racionalidade neoliberal é mais apropriadamente compreendido quando o vemos na forma de um esquema em que o mesmo paradigma que rege as ações do Estado está presente como ideal regulador na vida privada dos indivíduos: uma normatividade essencialmente econômica. De modo que "tanto pessoas quanto Estados constroem a si mesmos sob o modelo da firma contemporâneas" (BROWN, 2015, p. 22, tradução livre).

Essa analogia, por mais que tenha um papel esquemático e didático, evidencia de que maneira a análise proposta por Brown vai ao encontro da ideia foucaultiana de que os esquemas de normalização vigentes na sociedade como um todo se sustentam na medida em que são capazes de fazer com que cada indivíduo mantenha um domínio de si que está em consonância com eles. No caso da governamentalidade neoliberal, isso implica que a racionalidade eminentemente econômica que remodelou o Estado e o subordinou ao mercado é retroalimentada pelo fato de que os indivíduos que vivem sob sua jurisdição fazem dessa mesma racionalidade a orientação prática que governa suas próprias vidas.

Nessa toada, "Undoing the Demos", em certa medida, opera um deslocamento em relação ao enfoque anteriormente dado, no sentido de que a preocupação agora é de 
compreender não tanto o poder destrutivo do neoliberalismo, mas o seu poder produtivo, sendo esse um aspecto em que Brown permanece seguindo Foucault. Ou seja, não tanto a maneira como ele desgasta, desmonta, faz definhar; mas a maneira como ele toma para si a estrutura e os princípios do regime democrático para dar-lhes nova roupagem, transformarlhes o espírito, alterar seu propósito, fazer com que trabalhem a seu favor. Isso ao mesmo tempo em que ensina os indivíduos a se construírem como empresas humanas. Em autores abertamente neoliberais, como Gary Becker, por exemplo, encontra-se um verdadeiro projeto teórico de explicar o comportamento humano como manifestações diversas de uma mesma estrutura baseada em investimento e poupança de recursos, como em uma empresa real (FOUCAULT, 2008b). Para designar exatamente essa metamorfose silente da natureza originalmente política para uma natureza puramente econômica de instituições, práticas e princípios, a autora cria o conceito de "economização"4 (BROWN, 2015).

Nessa toada, Brown desenvolve uma análise sobre aspectos diversos das democracias contemporâneas, especialmente dos Estados Unidos, que atualmente estão passando por essa reconfiguração, indo desde a estrutura das universidades públicas à política externa. Para os propósitos deste artigo, é especialmente interessante apreciar, ainda que de maneira sucinta, a perspectiva que Brown formula no que diz respeito à liberdade de expressão e às mudanças no sistema de educação superior dos EUA.

Brown toma como paradigmático o precedente fixado pela Suprema Corte dos Estados Unidos no caso Citizens United v. Federal Election Comission, de 2010. A decisão em si foi no sentido de considerar inconstitucionais as normas que proibiam que corporações, ainda que de forma indireta, participassem do financiamento de campanhas eleitorais de candidatos a cargos eletivos. Os efeitos de uma tal decisão, obviamente, são antidemocráticos, na medida em que permitem que pessoas jurídicas, em função de seu patrimônio robusto, tenham uma influência desproporcional sobre as opiniões dos eleitores e sobre o resultado do pleito. A justificativa adotada no voto majoritário da decisão da Corte foi que isso configura uma forma legítima de exercício da liberdade de expressão.

No entanto, o aspecto enfocado por Brown é outro, muito mais difícil de perceber, e, por isso mesmo, muito mais pernicioso. Trata-se do fato de que compreender as ações das corporações como uma forma de exercício da liberdade de expressão só faz sentido uma vez que a premissa fundamental em torno desse direito básico é invertida. Não por outro motivo, o argumento do Juiz Kennedy, que propôs esse entendimento, foi no sentido de que a circulação

\footnotetext{
${ }^{4}$ Tradução adotada para a expressão "economization"
} 
de ideias e de opiniões dentro da sociedade, pelas mais diversas mídias e meios de comunicação, funciona tal como um mercado, em que as opiniões e posicionamentos são lançados ao público e chegam ao conhecimento de todas as pessoas. A cada um cabe escolher ao que aderir, quais posições endossar, da mesma maneira como um consumidor escolhe quais produtos comprar ou não (BROWN, 2015).

Não obstante, o mercado de ideias de que fala o Juiz Kennedy de forma alguma se confunde ao uso que a expressão "mercado de ideias" tem em John Stuart Mill, que famosamente a utilizou em sua discussão sobre a liberdade. Pois, se a preocupação de Mill era quanto à possibilidade de todos terem acesso às mais diversas opiniões, o voto do magistrado implica outra conotação. Segundo Kennedy, explica Wendy Brown “o discurso é o capital do mercado eleitoral, por isso necessariamente compartilha as características do capital: é apreciado pelo investimento calculado e promove a posição do seu detentor ou dono" (BROWN, 2015, p. 158, tradução livre).

Com isso, Brown aponta que, desse precedente em diante, a maneira de compreender a liberdade de expressão na jurisprudência americana mudou completamente. $\mathrm{O}$ valor do discurso e da expressão não reside mais em sua possibilidade de transmitir informações que servem à formação de opiniões, mas sim à valorização, em termos de capital humano, daquele que se expressa. Ter a possibilidade de se manifestar livremente é tanto melhor quanto mais permite ao indivíduo construir uma reputação, aumentar seu prestígio, trazer outros para o lado de suas reivindicações.

O problema com a consolidação desse entendimento é que ele refaz completamente o propósito da livre expressão de ideias em uma democracia. Isso porque, a partir do momento em que se entende que seu único propósito é servir ao indivíduo como um meio de melhorar sua posição, o livre discurso perde qualquer conexão com a esfera pública, com a responsabilidade pela reprodução de inverdades e com as consequências políticas de que esta ou aquela ideia se torne hegemônica.

Desse modo, o direito à liberdade de expressão é despido não apenas de seu propósito original (não permitir que ninguém seja violentado de qualquer maneira por expressar seu posicionamento) como também de seu próprio status como direito, tornando-se uma mera prerrogativa de participação em um mercado de ideias no sentido explicitado. No limite, a própria noção de esfera pública deixa de fazer sentido, e é substituída por uma versão do público como um ambiente análogo ao mercado, com a única diferença de que é 
movimentado não pelo dinheiro, mas pelo discurso. O discurso, conclui Brown, é convertido em uma forma de capital.

Algo semelhante e igualmente pernicioso acontece atualmente com a educação superior, diz Brown (2015). Quando se observa a história recente do ensino universitário estadunidense, nota-se que, após a Segunda Guerra Mundial ou um aumento significativo de acessibilidade por parte de indivíduos provenientes de grupos economicamente vulneráveis, sobretudo no que se refere à formação básica nas chamadas artes liberais. Embora, obviamente, assim como no Brasil, o acesso nunca tenha chegado perto do patamar ideal, é preciso atentar para o fato de que esse processo de inclusão proporcionou aos estudantes pelo menos um modesto horizonte de reversão de sua situação de pobreza.

Contudo, com a ascensão do neoliberalismo a partir da década de 1970, a estrutura de universidade passa por uma modificação radical. A qualidade das publicações é medida pelo seu impacto, indicador que tem a ver com a circulação do material publicado, a quantidade de citações e outros fatores numéricos. Uma métrica semelhante é estabelecida para determinar a distribuição de recursos entre os projetos de ensino, privilegiando aqueles de maior procura, ou os que oferecem as habilidades e competências mais valorizadas de acordo com cada setor do mercado.

Por último, a estrutura curricular dos cursos ofertados é remodelada à luz daquilo que é considerado como o conjunto das prováveis preferências de um estudante com vistas ao mercado de trabalho, de tal modo que o teor dos cursos passa a ser pensado em termos daquilo que parece mais atraente da perspectiva de um discente que pretende usar aquele processo de formação educacional como via de aquisição de competências que irão torná-lo mais apto à competição por postos de emprego. Em outras palavras, o ensino e a aprendizagem são colocados como uma forma de investimento em si que agrega valor.

Essa reformulação da universidade aos moldes da empresa desencadeias efeitos extremamente perversos. Um dos efeitos mais imediatos é a desvalorização e o sucateamento das humanidades, consideradas como um saber ocioso do ponto de vista da tecnocracia favorecida pelo modelo neoliberal, que só vê como valioso aquele conhecimento que proporciona calculabilidade e controle sobre o mundo. Maurizio Lazzarato oferece importante contribuição a esse respeito, ao demonstrar como a reorganização vivida pelo ensino universitário estadunidense constitui também uma forma de governo pela dívida. Ou seja, a formação superior oferecida nas universidades americanas é estruturada de tal maneira que, ao final do curso, o estudante contrai uma quantidade absurda de dívidas a serem quitadas 
frustram suas próprias aspirações de prosperidade econômica. Conclui o autor que "o endividamento dos estudantes é uma manifestação exemplar da estratégia neoliberal aplica desde os anos 1970" (LAZZARATO, 2013, p. 53, tradução livre).

Outro efeito, menos explícito, no plano da normatividade institucional, é que a ideia de formação profissional superior perde qualquer vínculo com as noções de bem comum. Com efeito, como muito bem explica Wendy Brown (2015), a educação concebida aos moldes neoliberais favorece a imagem do ensino profissionalizante como algo que só tem valor na medida em que confere aos discentes artifícios para elevar sua própria posição de competitividade. Portanto, nada tem a ver com a questão de formar cidadãos mais conscientes, ou sobre como o conhecimento é relevante para que cada um, na qualidade de cidadão, tenha condições de participar das deliberações coletivas de forma mais autônoma, racional e crítica. Muito menos com a ideia de que um profissional, depois de formado, tem qualquer contribuição a fazer para com a sociedade e em ajudar a promover o bem de todos.

\section{O fim do homo politicus}

Esses dois exemplos, sobre a conversão da expressão no âmbito público e da formação superior como formas diversas de capital, não são, como foi dito, a totalidade do diagnóstico de Brown. Porém, são bastante ilustrativos para compreender de que maneira a instauração da racionalidade neoliberal varre para o limbo do pensamento político as próprias bases da noção de cidadania. Isso porque a noção democrática e republicana de que cada cidadão é livre na medida em que vive sob leis cuja criação contou com a sua participação perde sentido completamente. Pois já não há mais cidadãos, apenas consumidores e empresários de si.

Além disso, a perspectiva oferecida pela autora sobre como o neoliberalismo coopta categorias e aparatos institucionais jurídicos para seus propósitos também representa um afastamento da posição original de Foucault a esse respeito. Nas palestras de 1979, Foucault (2008b), havia sustentado que o neoliberalismo se serve do direito sobretudo como uma estratégia de organização do mercado, desbloqueando os obstáculos à expansão da concorrência. Conforme apontado por Brown, contudo, pode-se perceber que a relação entre o direito e o neoliberalismo é bem mais complexa que essa.

Com efeito, em suas incursões sobre o ordoliberalismo em especial, Foucault destaca como essa vertente atribui um papel especial ao direito, na medida em que este funciona como aparato institucional que participa da produção do estado de coisas ideal para o florescimento da concorrência, aspecto este que Foucault chama de "intervencionismo jurídico" (FOUCAULT, 2008b, p. 230). Para além disso, como se observou, a análise de Brown mostra 
que o neoliberalismo, muito mais do que transformar o direito em um aspecto estratégico de organização social, drena o próprio sentido de institutos jurídicos e os enxerta com sua normatividade econômica. Fá-lo, porém, de maneira implícita e paulatina, de modo a manter uma aparência de incolumidade do direito quando na verdade seu conteúdo foi completamente contaminado pela concepção de mundo neoliberal (BROWN, 2015).

A partir do momento em que a liberdade de expressão é ressignificada como forma de capital e que os regulamentos legais, administrativos e disciplinares universitários são revistos para construir o ensino como forma de empreendimento, "o direito e o raciocínio jurídico não apenas dão forma ao econômico, mas economicizam novas esferas e práticas" (BROWN, 2015, p. 151, tradução livre). Como resultado, a linguagem e o vocabulário que constituem esses dois elementos como esteios da democracia são erodidos. Posto que essa linguagem e esse vocabulário político são condições de possibilidade para se pensar uma práxis democrática, esta última também se torna inconcebível. Metaforicamente, seria possível dizer que o direito passa a operar como uma espécie de mão de Midas, que desdemocratiza e economiciza aquilo que toca.

Isso nos leva ao que, dentre os apontamentos de Brown a respeito da leitura de Foucault sobre o neoliberalismo, talvez seja a maior insuficiência por ela destacada, qual seja, o fato de ele não ter atentado o bastante para o apagamento do homo politicus. No presente contexto, deve-se entender a expressão latina homo politicus como algo que designa todas as dimensões eminentemente políticas da vida humana, sejam elas compreendidas como disposições naturais à formação de coletividades e organização de instituições, sejam elas compreendidas como práticas sociais criadas artificialmente a fim de resolver problemas práticos que surgem com a presença humana no mundo.

De fato, conforme apontado anteriormente, Foucault notou uma importante transformação na política moderna, em que a vida biológica se tornou aspecto crucial da organização do poder, o qual se converteu em biopoder. Em célebre excerto, disse que por muito tempo o ser humano "permaneceu o que era para Aristóteles: um animal vivo e, além disso, capaz de existência política; o homem moderno é um animal em cuja política sua vida de ser vivo está em questão" (FOUCAULT, 2018, p. 155). O mérito de Foucault reside, então, em ter trazido à tona essa dimensão inédita da política que se centra sobre os aspectos biológicos da existência humana. Contudo, pouco teve a dizer sobre como a ascensão dessa mesma modalidade de poder, sob a figura do neoliberalismo, provocou o desaparecimento 
progressivo da dimensão política da vida humana, compreendida aqui na forma de atividades como o exercício da cidadania e de papéis ativos nas instituições.

Wendy Brown mobiliza a ideia de homo politicus justamente a fim de fazer um contraponto à apoteose do homo oeconomicus referida por Foucault. Isso porque se, por um lado, Foucault (2008b) estava certo em afirmar que o neoliberalismo cria um modelo teórico inédito, por conceber o ser humano como um ente exclusivamente dotado de racionalidade econômica, ele deu pouca atenção, por outro lado, a como isso implica um apagamento da distinção qualitativa entre atividades humanas políticas (no sentido mencionado há pouco) e atividades humanas puramente econômicas, distinção essa que, segundo a pensadora em questão, foi uma constante durante toda a história do pensamento filosófico ocidental.

De fato, Brown é assertiva e extremamente precisa em demonstrar como, em todos os grandes sistemas filosóficos desenvolvidos desde os gregos, a política sempre foi concebida como um domínio de natureza própria e, o mais importante, irredutível a formas de racionalidade de outros tipos. Para dar apenas alguns dos exemplos perpassados pela análise de Brown, Aristóteles firmemente defendeu que os interesses pessoais das atividades do comércio e do artesanato não deveriam contaminar as discussões da ágora. Smith argumentou que a existência do mercado só é possível subsidiariamente em relação a práticas simbólicas de linguagem e comunicação que o precedem. Locke afirmou que a defesa dos direitos naturais é do interesse de todos, independentemente dos ganhos que isso possa trazer a este ou àquele indivíduo. Bentham, embora tenha dito que os seres humanos são governados por dor e prazer, sustentou que essa natureza humana une a todos e cria uma rede de interesses comuns que as instituições devem proteger (BROWN, 2015).

Nesse sentido, um breve exame de toda essa extensa tradição de pensamento revela que a tentativa de conceber o ser humano como sendo nada mais do que um otimizador de resultados jamais foi esboçada. Nem mesmo no caso do liberalismo clássico, frequentemente referenciado como criador da noção de homo oeconomicus, essa perspectiva nunca esteve em jogo. Em verdade, uma diferença fundamental dessa ideologia política - que tem em Smith e Locke duas de suas mais proeminentes figuras - em relação ao neoliberalismo é que, para os liberais clássicos, as liberdades civis e o livre mercado produzem efeitos positivos para a totalidade dos indivíduos, inclusive para os menos favorecidos.

Tal promessa está ausente no pensamento neoliberal. Em verdade, como destacam Dardot e Laval (2016) uma coisa que o neoliberalismo enfatiza é que a saúde do livre mercado por vezes implica certos sacrifícios, de sorte que a negação de garantias de bem-estar 
para alguns indivíduos é parte natural e plenamente aceitável do modo de funcionamento regular do mercado. Disso decorre que condições como a pobreza e a vulnerabilidade econômica não merecem um tratamento jurídico específico, mas devem ser compreendidas apenas como situações em que os indivíduos recaem como resultado de sua incompetência ou imperícia em serem bons administradores de suas próprias vidas e de terem responsabilidade a respeito dos riscos envolvidos.

Não obstante, ao longo de suas análises sobre a governamentalidade neoliberal, Foucault pouco abordou o desaparecimento do homo politicus. Quando muito, trata do homo legalis, que tem a ver com um certo aspecto jurídico em que o ser humano é concebido como um ente capaz de sustentar pretensões e de fazer reivindicações em face de outros seres humanos. Mas a ideia por trás de homo legalis tem muito mais a ver com defesa de interesses próprios do que com a questão da cidadania ou com a participação na tomada de decisões que definem os rumos da comunidade política.

Nessa linha de raciocínio, faltou a Foucault, diz Brown, atentar para o fato de que o homo oeconomicus neoliberal só foi capaz de prevalecer na medida em que o homo politicus foi paulatinamente suprimido. Essa inflexão no imaginário político é peça fundamental do projeto neoliberal, e é a partir dela que o processo de economização elucidado por Brown se torna possível, já que seu propósito é operar uma identificação do político com o econômico, ou melhor, reduzir o político a um caso particular do raciocínio econômico, considerado como universal.

\section{Por que a democracia liberal importa?}

Depois de levar a cabo seu ambicioso e relevantíssimo projeto de entender como o neoliberalismo mata o espírito da democracia e a transforma em uma casca vazia que pode ser preenchida segundo seus propósitos, Wendy Brown se coloca uma questão de suma importância: por que o colapso da democracia liberal é algo a se lamentar?

De fato, é preciso admitir que a resposta a essa questão não é exatamente óbvia. Afinal, as mais diversas abordagens críticas -do marxismo ao pós-estruturalismo, passando pelas várias correntes do feminismo, do pensamento pós-colonial e decolonial, para não falar da luta antirracista- concordam, por motivos variados, que a democracia liberal é um dos regimes políticos mais contumazes em apresentar a si mesma como realizadora de justiça e igualdade ao mesmo tempo em que oculta formas de opressão. Seja porque o liberalismo político se apoia em um discurso universalista vazio, seja porque há uma naturalização da 
relação capital-trabalho, seja porque os processos eleitorais não refletem a pluralidade da sociedade.

Sendo assim, o fato de que um tal regime esteja em vias de ser superado, por si mesmo, não é um fato diretamente lamentável. Se de fato o é, como Brown acertadamente afirma, é porque aquilo que o está substituindo é um estado de coisas ainda pior. Nesse sentido, caberia perguntar o que há na democracia liberal, a despeito de todos os seus problemas, que torna seu desmantelamento algo negativo. Ou seja: qual é o elemento positivo que está contido na democracia liberal, apesar de todas as suas insuficiências, que tende a desaparecer com a implantação do neoliberalismo?

A partir das análises que acompanhamos até aqui, Brown responde que, além de todo o aumento das desigualdades e políticas de morte que o neoliberalismo desencadeia, o seu golpe fatal é desferido sobretudo sobre a discursividade e sobre o imaginário político universalista da democracia liberal, o qual, por mais problemático que seja, ainda possui algum vislumbre de potencial emancipatório residual. Baseando-se no argumento de Marx (2010) em seu célebre texto "Sobre a questão judaica", Wendy Brown sustenta que, por mais que as ideias que habitam o coração da democracia liberal, como isonomia, igualdade de tratamento perante a lei, sufrágio universal e outras, nunca tenham sido efetivadas no plano da realidade de maneira a realmente atingir todos os indivíduos, elas ainda assim são capazes de funcionar como um horizonte axiológico a partir do qual é possível fazer reivindicações e denunciar injustiças (BROWN, 2015).

Nesse texto de 1843, Marx tece uma crítica voraz aos tão celebrados Direitos do Homem e do Cidadão, considerados pela sociedade burguesa como uma das grandes conquistas civilizatórias em relação ao Antigo Regime. Contra a ideia falaciosa de que essa tábua de direitos teria inaugurado uma era de liberdade, igualdade e fraternidade entre os seres humanos, Marx dirá que esses direitos são um aparato jurídico projetado para servir somente àqueles indivíduos que detêm uma posição social avantajada o bastante para definirem suas aspirações e perseguirem-nas livremente, bastando, para isso, estarem isentos de coerção por parte de outrem e do Estado. Por esse motivo, asseverou que "nenhum dos assim chamados direitos humanos transcende o homem egoísta” (MARX, 2010, p. 50).

Apesar disso, Marx reconhece que há pelo menos um aspecto da ordem burguesa dos direitos que não é de todo descartável. Pois é justamente aí, nesse hiato entre as promessas abstratas não cumpridas de liberdade, igualdade e fraternidade, de um lado, e a realidade crua e prenhe de injustiças, do outro, que reside a possibilidade de conceber a perspectiva de uma 
sociedade mais justa. Em outras palavras, o próprio universalismo falacioso, devido à sua efetivação incompleta, contém os elementos que apontam para a sua denúncia, que toma a forma de uma exigência de extensão daquelas promessas à totalidade dos indivíduos.

No mesmo sentido, Wendy Brown argumenta que, se a democracia liberal de fato não cumpre com tudo aquilo que diz cumprir, ela ao menos contém um vocabulário e um conjunto de ideias que podem funcionar como matéria prima da crítica da opressão e da elaboração de uma práxis emancipatória. Essas ideias e esse vocabulário têm a ver com as noções básicas de cidadania, de autonomia política, de soberania popular e tantas outras. O trabalho pernicioso do neoliberalismo é o de sufocar uma a uma dessas ideias, substituindo-as, como explicitado, por noções puramente de uma métrica econômica, insensível às injustiças da realidade. $\mathrm{O}$ problema, diz Wendy Brown, é que a esquerda política ainda não foi capaz de articular um projeto sustentável que pudesse se opor à cosmovisão neoliberal sem se limitar a uma simples defesa da democracia liberal e do bem-estar social. Enquanto tal projeto não existir, a marcha da desdemocratização não cessará.

\section{Conclusão}

O trabalho buscou compreender de que maneira Wendy Brown emprega as categorias desenvolvidas por Foucault para fins de sua análise do neoliberalismo contemporâneo. Como foi possível observar, a leitura que a pensadora faz do autor não permaneceu a mesma ao longo de sua carreira, mas sim passou por várias modificações.

Nos textos iniciais, que representaram os primeiros esforços de Brown de lançar luz sobre esse avassalador capítulo da história mundial chamado neoliberalismo, Foucault foi compreendido como o autor para quem o neoliberalismo não se explica somente como uma nova fase do modo de produção capitalista, muito menos como uma renovação de preceitos do liberalismo clássico, e, sim, como uma forma inédita de racionalidade abrangente. Brown se inspira nessa premissa e faz um interessante levantamento sobre quais esteios do imaginário político contemporâneo a razão neoliberal necessariamente tem de atacar e desconstruir para se fixar como hegemônica, e um dos alvos preferenciais são os ideais normativos que animam a democracia liberal tal como a conhecemos.

Nesses mesmos textos, também se detectou uma motivação que tem a ver com as manifestações de autoritarismo do governo G.W. Bush. Para ser mais exato, uma preocupação em entender o que possibilitava que o modus operandi autoritário após o onze de setembro fosse normalizado no funcionamento das instituições. Nesse ponto, novamente, Brown lança mão da visão do neoliberalismo como forma de racionalidade para dizer que o modelo de 
sociedade neoliberal é despido de qualquer compromisso ético-político substantivo em vez de meramente formal, de modo que a própria fronteira entre o que é aceitável e o que é inaceitável se dissolve, criando uma permeabilidade que possibilita o flerte entre neoliberalismo e neoconservadorismo.

Já no que se refere à obra madura e mais recente de Brown, observou-se que, apesar de Foucault ainda figurar como referencial teórico central, o número de problematizações e correções que a autora dirige a ele é bem maior. A começar pelo modo como Foucault havia constatado a relação entre neoliberalismo e direito, que, para Brown, ainda era limitada e magra demais para captar de que maneira o neoliberalismo utiliza o direito para estender sua epistemologia economicista para outros aspectos da vida política, refazendo o propósito e o sentido original de instituições centrais como a esfera pública e a universidade. Além disso, Foucault teria enfocado exclusivamente a afirmação do homo oeconomicus e praticamente ignorado o apagamento do homo politicus.

A fim de dar conta dessas insuficiências e criar categorias de análise adequadas ao momento presente, Brown cria o conceito de economização e usa-o como explicação para o fenômeno da desdemocratização que ora ocorre. Dessa maneira, Brown soube, de maneira brilhante e exemplar, tomar a perspectiva oferecida por Foucault e interpretá-la a ponto de extrair consequências normativas importantes. Nesse sentido, seu diagnóstico, dotado de originalidade, representa uma compreensão precisa do neoliberalismo e referência indispensável para se começar a pensar formas de resistência e emancipação.

\section{REFERÊNCIAS BIBLIOGRÁFICAS}

BROWN, Wendy. American Nightmare: Neoliberalism, Neoconservatism and DeDemocratization. Political Theory, Berkeley vol. 34, n. 6, p. 690-714, dez. 2006.

BROWN, Wendy. Undoing the Demos: Neoliberalism's Stealth Revolution. Cambridge: Zone Books, 2015.

BROWN, Wendy. Edgework: Critical Essays on Knowledge and Politics. Princeton: Princeton University Press, 2005.

DARDOT, Pierre; LAVAL, Christian. A Nova Razão do Mundo: Ensaio sobre a Sociedade Neoliberal. Tradução de Mariana Echalar. São Paulo: Boitempo, 2016.

FOUCAULT, Michel. Segurança, Território, População: curso dado no Collège de France (1977-1978). Tradução de Eduardo Brandão. São Paulo: Martins Fontes, 2008a.

FOUCAULT, Michel. Nascimento da biopolítica: curso dado no Collège de France (19781979). Tradução de Eduardo Brandão. São Paulo: Martins Fontes, 2008 b. 
FOUCAULT, Michel. Em defesa da sociedade: curso dado no Collège de France (19751976). Tradução de Maria Ermantina Galvão. São Paulo: Martins Fontes, 2010.

FOUCAULT, Michel. História da Sexualidade 1: a vontade de saber. Tradução de Maria Thereza Albuquerque e J.A. Albuquerque. Rio de Janeiro: Paz e Terra, 2018.

HARVEY, David. O neoliberalismo: história e implicações. Tradução de Adail Sobral e Maria Stela Gonçalves. 5. ed. São Paulo: Edições Loyola, 2014.

LAZZARATO, Maurizio. Il governo dell'uomo indebitato: saggio sulla condizione neoliberalista. Roma: Derive Approdi, 2013.

LEMKE, Thomas. "The birth of biopolitics": Michel Foucault's lecture at the Collège de France on neo-liberal governmentality. Economy and Society, Londres vol. 30, n. 2, p. 190207, 2001.

MARX, Karl. Sobre a Questão Judaica. Tradução de Nélio Schneider. São Paulo: Boitempo, 2010.

Artigo recebido em: 30/06/20

Artigo aprovado em: 03/09/20 